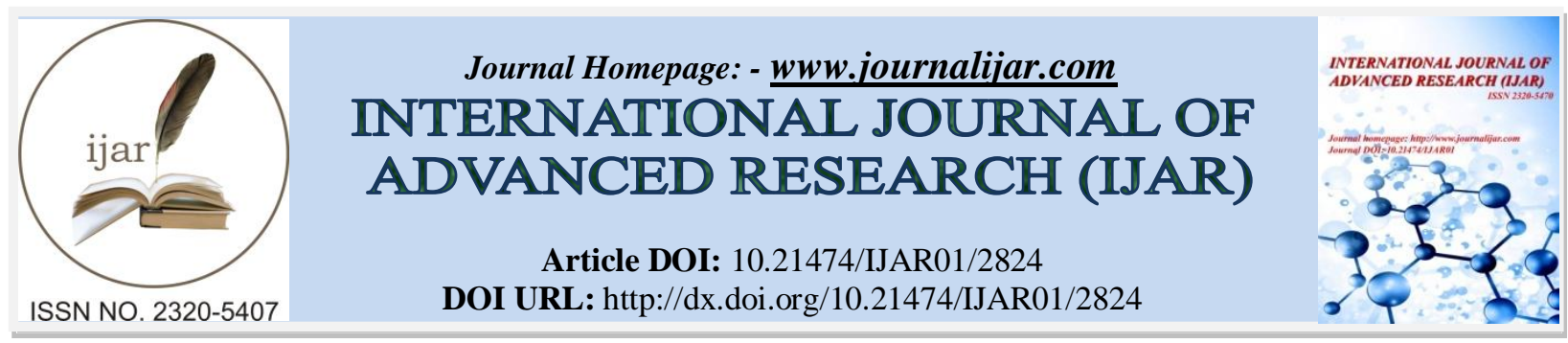

RESEARCH ARTICLE

\title{
DEVIANT BEHAVIOUR ELICITED BEFORE DETENTION BY THE MALAY FEMALE JUVENILE DETAINEES IN REHABILITATION CENTER
}

\author{
Junainor Hassan, Salleh Abd Rashid, Hassad Hassan and Siti Norayu Mohd Basir. \\ School of Human Development and Technocommunication, Universiti Malaysia Perlis, Jejawi Office, 06200 Jejawi, \\ Arau, Malaysia
}

\section{Manuscript Info}

...........................

Manuscript History

Received: 17 November 2016

Final Accepted: 18 December 2016

Published: January 2017

\section{Key words:-}

female juvenile detainees, deviant behaviour, school vandalism, beating, harassment, sexual harassment.

\section{Abstract}

The objective of this study is to examine the Malay female juvenile detainees' deviant behavior before detention in rehabilitation institution. This study uses quantitative method. There were 41 respondents participated in this critical case study. Hence, data was collected using self-build instrument with 20 items and the reliability of cronbach alpha is 0.715 . The finding of this study shows the most frequent deviant behavior elicited according to category were as follows: school vandalism, beating, harassment and sexual harassment. The places of eliciting deviant behaviour according to highest and lowest score; first, during recess hours in classroom, field or hall; near or under the stairs; and in the students' toilet. Second, during recess hours while taking food. Third, in the classroom while the teacher is teaching. Forth, during recess hour while eating. Fifth, while walking between change of class. Sixth, while walking between to and fro to the praying house; in the classroom before teacher enters the class and while queuing to buy food and seventh, during recess hour while taking food and eating in the canteen. Few unique findings in this study; first, only 1 respondent involved in doing damages to the school's playground facilities. Second, the area which mostly displayed of deviant behaviour was in the open area. Third, the act of deviant behaviour in classroom while a teacher is teaching and low score on deviant behaviour elicited during recess hour while eating, walking between change of classes, walking between to and fro to the praying house; in the classroom before teacher enters the class; while queuing to buy food, while taking food and eating in the canteen.

Copy Right, IJAR, 2016,. All rights reserved.

\section{Introduction:-}

Deviant behaviour of young adolescent is seen nowadays as a serious scenario as it hint on the corruption of morality of our younger generations especially in Malaysia which embraces so called the 'Malaysian Culture'. Nonetheless, the Malaysian culture and norms are changing due to the in-flow of other cultures into the society through the medium called 'borderless world' via social media (internet) as a medium of change and the influence of either broadcast and printed media itself (Bassey; Makinde; Rasheed; \&Olumide, 2013; Baron, 2003). Nowadays, deviant behavior is seen 'acceptable' to our youngsters and now regarded as the 'trend' (Turner, 1987), that one must agree and follow if to be accepted (in group) in his or her community (Baker, 2006). 
As quoted by Duffy \&Nesdale (2004), younger generations tend to behave 'out of their norms' as they are in their development stage of finding and building their own unique personality (traits) especially female (Unruh, Povenmiro-Kirk \& Yamamoto, 2009). They wanted to have their own unique identity and be acknowledged by their peers (Ojala, Kris \&Nesdale, Drew, 2004), whereby normally will involve the factors of power, wealth, strength and popularity (Paluck, Elizabeth Levy \& Shepherd, Hana, 2012).

Subsequently, school is a place whereby most of youngsters spend their time and mingling with their own society which in a way acted as a perfect medium in eliciting deviant behaviour (Wan Pung,Pit; Yaacob, Siti Nor; Baharudin, Rozumah\& Osman, Shuhaily, 2015), as the internal and external influence factors were so strong (Borum, 2000). Furthermore, school is the common ground for youngsters to show the sense of belonging' and embrace the concept of cohesiveness between group members (Paluck, Elizabeth; \& Shepherd, 2012), which is a strong virtue among females (Weerman, F. M., \&Hoeve, M., 2012).

Therefore, deviant behaviour if were not controlled can lead to crimes which has made juveniles being arrested and evicted into correctional schools and rehabilitation centers. In Malaysia alone, there were evicted cases of 29,642 juveniles detained into either correctional schools or rehabilitation centers all over the states in Malaysia in 2011 (Statistic Service, Malaysia \&Department ofSocial Welfare, 2013).

Study framework:-

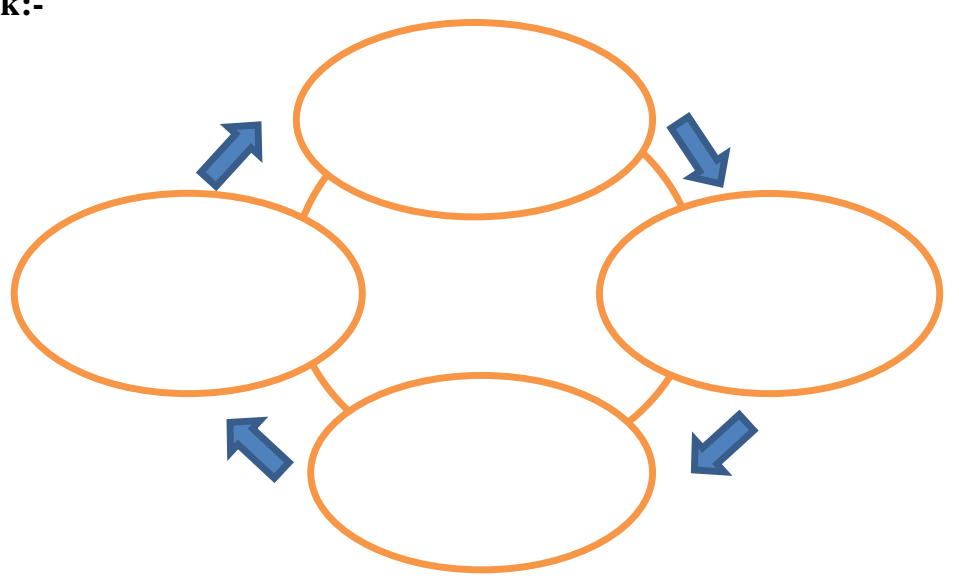

\section{Research question:-}

There are two research questions explored in this study:-

1. What are the types of deviant behavior elicited by the Malay female juvenile detainees in school before detention? And

2. The most common places of deviant behaviour elicited in school compound.

\section{Main objective:-}

The main objective of this study is to determine the Malay female juvenile detainees' deviant behaviour and where does the deviant behaviour elicited in school compound.

\section{Specific objectives:-}

1. To determine the Malay female juvenile detainees' deviant behaviour in school.

2. To determine the places in school compound that frequently visited by the Malay female juvenile detainees in eliciting deviant behaviour.

3. To examine the relationship between deviant behaviour in each category of school vandalism, beating, harassment and sexual harassment.

\section{Hypotheses:-}

Hypotheses were built according to the objectives of the study:

1. To determine the Malay female juvenile detainees' deviant behaviour in school.

Frequencies of Malay female juvenile detainees' deviant behavior according to category: 


$\begin{aligned} \text { i. } & \text { School vandalism } \\ \text { ii. } & \text { Beating } \\ \text { iii. } & \text { Harassment } \\ \text { iv. } & \text { Sexual harassment }\end{aligned}$

2. To determine the places in school compound that frequently visited by the Malay female juvenile detainees in eliciting deviant behaviour.

Frequencies of places in school compound which was visited by the Malay female juvenile detainees' before detention in eliciting deviant behaviour.

3. To examine the relationships between deviant behaviour in each category; school vandalism, beating, harassment and sexual harassment.

$\mathrm{H}_{\mathrm{a} 1}$ There were significant relationships between deviant behavior in each category of school vandalism, beating, harassment and sexual harassment.

\section{Significant of study:-}

This study is significant to:-

School and any parties concerned in promoting awareness programme. It is also important to identify the dangerous zone in school compound so that the authorities in school were kept alert on high risk areas and thus take precaution measures such as installing recording equipment ie. closed-circuit television.

\section{Limitation of study:-}

As of security and safety issues; name of the respondents, rehabilitation center and schools involved in this study was kept confidential.

\section{Methodology:-}

\section{Population and sampling technique:-}

The population of this present study were Malay female juvenile detainees in a rehabilitation center. As this is a critical case study, there were only $n=41$ Malay female juvenile respondents involved in this study with ( $\mathrm{n}=11$; age 17 years old); ( $\mathrm{n}=8$; age 18 years old); ( $\mathrm{n}=7$; age 15 years old); $(\mathrm{n}=5$; age 14 years old); $(\mathrm{n}=5$; age 16 years old) and, $(\mathrm{n}=5$; age 19 years old $)$.

\section{Data Collection Procedure:-}

The questionnaires were self-administered by the researcher. Self-build instrument was being distributed and respondents were asked to answer the questions within 20 to 25 minutes.

\section{Instrument:-}

This study uses self-build instrument with 20 items. The reliability of this instrument is 0.715 .

\section{Data Analysis:-}

Data was analyzed using the SPSS version 21. Frequency and descriptive analysis was utilized as to determine the Malay female juvenile deviant's behaviour in school compound before detention. Meanwhile, the correlational analysis is used to find the significant relationships between deviant behaviour and places visited by the Malay female juvenile detainees in school compound.

\section{Findings:-}

1. To determine the Malay female juvenile detainees' deviant behaviour in school.

Frequencies of Malay female juvenile detainees' deviant behavior according to category:

i. School vandalism

ii. Beating

iii. Harassment

iv. Sexual harassment 
Table 1:- Frequencies of deviant behaviour according to category

\begin{tabular}{|c|c|c|}
\hline & Mean & sd. \\
\hline School vandalism & 10.0732 & 1.95436 \\
Beating & 6.8293 & 3.47780 \\
Harassment & 5.9268 & 3.45246 \\
Sexual harassment & 0.8780 & 1.67623 \\
\hline
\end{tabular}

Table 1 summarized the most frequent deviant behaviour elicited by the Malay female juvenile detainees before detention in school compound according to category; the school vandalism $\left({ }^{-} \mathrm{x}=10.0732\right)$; beating $\left({ }^{-} \mathrm{x}=6.8293\right)$; harassment $\left({ }^{-} \mathrm{x}=5.9268\right)$; and sexual harassment $\left({ }^{-} \mathrm{x}=0.8780\right)$.

School vandalism:-

Table 2:- Percentages of deviant behaviour according to school vandalism category

\begin{tabular}{|c|c|c|}
\hline & Frequency & \multicolumn{2}{c|}{$\%$} \\
\hline Equipment-facilities & 37 & 56.2 \\
Canteen-facilities & 23 & 43.9 \\
Teacher's transportation & 18 & 4.9 \\
Parent's-other's transportation & 2 & 2.4 \\
Playground facilities & 1 & \\
\hline
\end{tabular}

Table 2 reports on deviant behaviour with 37 (90.2\%) respondents vandalized on school equipment and facilities; 23 (56.1\%) respondents damages on school canteen and facilities; 18 (43.9\%) respondents vandalized on teacher's transportation with $2(4.9 \%)$ respondents scratches on parents or other transportation. The lowest score is 1 (2.4\%) respondent vandalizing on school's playground facilities.

Table 3:- Relationship between deviant behaviour in school vandalism category

\begin{tabular}{|l|c|c|c|c|c|}
\hline & $\begin{array}{c}\text { School } \\
\text { vandalism1 }\end{array}$ & $\begin{array}{c}\text { School } \\
\text { vandalism2 }\end{array}$ & $\begin{array}{c}\text { School } \\
\text { vandalism3 }\end{array}$ & $\begin{array}{c}\text { School } \\
\text { vandalism4 }\end{array}$ & $\begin{array}{c}\text { School } \\
\text { vandalism 5 }\end{array}$ \\
\hline $\begin{array}{l}\text { School } \\
\text { vandalism1 }\end{array}$ & 1 & & & & \\
\hline $\begin{array}{l}\text { School } \\
\text { vandalism2 }\end{array}$ & -.200 & 1 & 1 & & \\
\hline $\begin{array}{l}\text { School } \\
\text { vandalism3 }\end{array}$ & .125 & $-.689^{* *}$ & -.291 & & \\
\hline $\begin{array}{l}\text { School } \\
\text { vandalism4 }\end{array}$ & .089 & .200 & .052 & & .140 \\
\hline $\begin{array}{l}\text { School } \\
\text { vandalism5 }\end{array}$ & -.140 & -.036 & & & 1 \\
\hline
\end{tabular}

$* * \mathrm{p}<0.01$

$* \mathrm{p}<0.05$

Table 3 shows the result of correlation analysis to examine the relationship between each deviant behaviour in school vandalism category. There was a significant relationship between vandalizing on school equipment and facilities and, damages on school canteen and facilities $(r=-.689, \mathrm{p}<0.01)$.

\section{Beating:-}

Table 4:- Percentages of deviant behaviour according to beating category

\begin{tabular}{|c|c|c|}
\hline & Frequency & \multicolumn{2}{c|}{} \\
\hline Classmates & 27 & 36.9 \\
Friends-from other class & 15 & 19.5 \\
Other students & 8 & 9.8 \\
Friends-from home & 4 & 7.3 \\
\hline Friends from other areas & 3 & \\
\hline
\end{tabular}

Table 4 reports on percentages of deviant behaviour according to beating category with $27(65.9 \%)$ respondents beats their classmates; $15(36.6 \%)$ respondents beats their friends from other classes; $8(19.5 \%)$ respondents beats on 
other students; 4 (9.8\%) respondents beats on friends from home and $3(7.3 \%)$ respondents beats friends from other areas.

Table 5:- Relationship between deviant behaviour in beating category

\begin{tabular}{|l|c|c|c|c|c|c|}
\hline & Beat1 & Beat2 & Beat3 & Beat4 & Beat5 & Beat6 \\
\hline Beat1 & 1 & & & & & \\
\hline Beat2 & -.094 & 1 & & & & \\
\hline Beat3 & -.165 & .137 & 1 & & & \\
\hline Beat4 & -.110 & -.250 & -.162 & 1 & & \\
\hline Beat5 & -.193 & -.019 & -.138 & -0.92 & 1 & \\
\hline Beat6 & $.504^{*}$ & .082 & -.194 & .224 & -.211 & 1 \\
\hline
\end{tabular}

$* * \mathrm{p}<0.01$

$* \mathrm{p}<0.05$

Table 5 shows the result of correlation analysis to examine the relationship between each deviant behaviour in beating category. There was a significant relationship between others and friends from other areas $(r=-.504$, $\mathrm{p}<0.01)$.

Harassment:-

Table 6:- Percentages of deviant behaviour according to harassment category

\begin{tabular}{|c|c|c|}
\hline & Frequency & $\%$ \\
\hline Classmates & 40 & 97.6 \\
Friends from other class & 5 & 12.2 \\
\hline Friends from home & 4 & 9.8 \\
Other students & 3 & 7.3 \\
\hline
\end{tabular}

Table 6 reports on percentages of deviant behaviour according to harassment category which indicates physical, verbal and relational bullying. There were a total of 40 (97.6\%) respondents harassing their classmates; 5 (12.2\%) respondents harassing friends from other classes; $4(9.8 \%)$ respondents harassing friends from home but who were schooling in the same school and $3(7.3 \%)$ respondents harassing other students which is from the same standard/secondary level.

Table 7:- Relationship between deviant behaviour in harassment category

\begin{tabular}{|l|c|c|c|c|c|}
\hline & Harass1 & Harass2 & Harass3 & Harass4 & Harass5 \\
\hline Harras1 & 1 & & & & \\
\hline Harras2 & .059 & 1 & & & \\
\hline Harras3 & .044 & -.105 & 1 & & \\
\hline Harass4 & .052 & .129 & -.092 & 1 & \\
\hline Harass 5 & -.108 & .254 & -.211 & .224 & 1 \\
\hline
\end{tabular}

$* * \mathrm{p}<0.01$

$* \mathrm{p}<0.05$

Table 7 shows the result of correlation analysis to examine the relationship between each deviant behaviour in harassment category. There is no significant relationship between each deviant behavior in harassment category.

Sexual harassment:-

Table 8:- Percentages of deviant behaviour according to sexual harassment category

\begin{tabular}{|c|c|c|}
\hline & Frequency & $\%$ \\
\hline Classmates & 8 & 19.5 \\
Friends from other classes & 4 & 9.8 \\
Friends from other areas & 4 & 9.8 \\
\hline
\end{tabular}

Table 8 reports on percentages of deviant behaviour according to sexual harassments that were mostly on non-verbal gestures and touching inappropriate body parts. $8(19.5 \%)$ respondents sexually harassed their classmate either girls 
or boys; $4(9.8 \%)$ respondents sexually harassed friends from other classes and $4(9.8 \%)$ sexually harassed friends from other areas.

Table 9:- Relationship between deviant behaviour in sexual harassment category

\begin{tabular}{|c|c|c|c|}
\hline & Sex harass1 & Sex harass2 & Sex harrass3 \\
\hline Sex harass1 & 1 & & \\
\hline Sex harass2 & -.162 & 1 & 1 \\
\hline Sex harass3 & -.162 & .169 & \\
\hline
\end{tabular}

$* * \mathrm{p}<0.01$

$* \mathrm{p}<0.05$

Table 9 shows the result of correlation analysis to examine the relationship between each deviant behavior in sexual harassment category. There is no significant relationship between each deviant behavior in sexual harassment category.

2. To determine the places in school compound that frequently visited by the Malay female juvenile detainees in eliciting deviant behaviour.

Frequencies of places in school compound which was visited by the Malay female juvenile detainees' before detention in eliciting deviant behaviour.

Table 10:- Frequencies of location in school compound in which deviant behaviour was elicited

\begin{tabular}{|c|c|c|}
\hline & Frequency & Percentage \\
\hline During recess(classroom/field/hall) & 98 & 89.1 \\
Near/under stairs & 98 & 89.1 \\
In students' toilet & 98 & 89.1 \\
During recess (while taking food) & 88 & 80 \\
In classroom (while teacher is teaching) & 76 & 69.1 \\
During recess (while eating) & 31 & 46.4 \\
Walking between change of classes & 16 & 33.6 \\
Walking between to and fro to praying house & 16 & 14.5 \\
Walking to and fro to praying house & 16 & 14.5 \\
In classroom (before the entrance of teacher) & 16 & 14.5 \\
During recess (queuing to buy food) & 9 & 14.5 \\
During recess (while taking food) & 9.2 \\
During recess (while eating) & 8.2 \\
\hline
\end{tabular}

Table 10 reported on the most frequent places in school compound in which deviant behavior was elicited. The most frequent compound that scores $89.1 \%$ was during recess hours in classroom, field or hall; near or under the stairs; and in the students' toilet. Second, is during recess hour while taking food that has a score of $80 \%$. Next is in the classroom while the teacher is teaching with a score of $69.1 \%$. 46.4\% score during recess hour while eating followed by walking between changing of classes with a score of 33.6\%. Meanwhile, walking between to and fro to the praying house; in the classroom before teacher enters the class; during recess hour while queuing to buy food has the same score of $14.5 \%$. Subsequently, $8.2 \%$ score while taking food and eating in canteen during recess hour.

3. $\quad \mathrm{H}_{\mathrm{a} 1}$ There were significant relationships between deviant behaviour in each category of school vandalism, beating, harassment and sexual harassment.

Table 11:- Relationship between deviant behaviour in each category

\begin{tabular}{|c|c|c|c|c|}
\hline & $\begin{array}{c}\text { School } \\
\text { vandalisme }\end{array}$ & Beating & Harassment & Sexual harassment \\
\hline School vandalisme & 1 & & & \\
\hline Beating & $.373^{*}$ & 1 & & \\
\hline Harassment & $.357 *$ & $.788 * *$ & 1 & \\
\hline Sexual harassment & .127 & .236 & .183 & 1 \\
\hline
\end{tabular}


$* * \mathrm{p}<0.01$

$* \mathrm{p}<0.05$

Table 11 indicated on the result of correlation analysis to examine the relationship between deviant behaviour in each category of school vandalism, beating, harassment and sexual harassment. Results shows that the most significant relationship can be found between beating and harassment $(r=0.788, p<0.01)$, followed by between beating and school vandalism $(r=0.373, \mathrm{p}<0.01)$; and between school vandalism and harassment $(\mathrm{r}=0.357, \mathrm{p}<0.01)$.

\section{Conclusion and Discussion:-}

The study has shown that the Malay female juvenile detainees were prone to vandalized school and canteen, equipment and facilities. This study also indicates strong vindictive behaviour of the Malay female juvenile detainees towards teaching staff when $43.9 \%$ admitted vandalizing their teacher's transportation. One unique finding on this study is that only $2.4 \%$ or 1 respondent involved in doing damages to the school's playground facilities. The assumption of this finding is that; the Malay female juvenile detainees had profound belonging awareness and the need to care on things that makes them happy.

Finding of this study also reported on the Malay female juvenile detainees who targeted those who were within their school socialization or communities in inflicting beating behaviour such as classmates, friends from other classes and other students who were schooling in the same school but not in the same standard or secondary level. All of these targeted victims went to the same school but they were not in the same area of residencies with the Malay female juvenile detainees. However, low rate of inflicting beating were to those who were from the same residency areas (where the Malay female juvenile detainees resides) and those who were from other areas.

This was probably, the Malay female juvenile detainees did not want to provoke or steer any unpleasant situation between their families and other families (community members where they resides) that know or who has established relationship with their families. It is the same with harassment behaviour which were mostly inflicted on those who were in the same school as the Malay female juvenile detainees but resides in different residency areas from the Malay female juvenile detainees. Nevertheless, few Malay female juvenile detainees involved in sexual harassment and the score is low as not more than $20 \%$ admitted in sexually harassed their classmates, friends from other classes and friends from other areas.

As for dangerous time and places in school compound where deviant behaviour mostly occurs; this study has concluded that the high risk time of eliciting deviant behaviour among Malay female juvenile detainees before detention was during recess hours. Surprisingly, the area which mostly displayed of deviant behaviour was in open area that is in the classroom, on field or at the school hall and in the canteen. The most probable reason; it is where the Malay female juvenile detainees was with their group of friends (in group) which has already retained and practices certain standard of acceptable behaviour such as bullying towards others who were not in their group (out group).

Another dangerous zone is under the stairs and in the student's toilet which is understandable as these is the 'dark' and secluded area where there were not so many visitors. Thus, it is easier for the Malay female juvenile detainees to take the opportunities to inflict deviant behaviour on other students as they felt safe. Furthermore, the chances of having no witnesses to anything that they might do to other students appealed them to go to these places in the first place.

Another interesting finding in this study is the Malay female juvenile detainees who without fear show deviant behaviour in the classroom while a teacher is teaching. It proves that there were changes in the Malay culture which were famously known to have highly respects on elders and to those who has the authority of nurturing and educating people especially in rural areas. It might also be an indicator of these Malay female juvenile detainees experiencing boredom in class as a result of not being able to understand the subjects taught or has not put any kind of interest in the subjects taught by the teacher and thus, creating 'negative event' such as picking on others to amused and entertained themselves.

Another intriguing finding is that the low score of deviant behaviour elicited during recess hour while eating, walking between change of classes, walking between to and fro to the praying house; in the classroom before teacher enters the class; while queuing to buy food, while taking food and eating in the canteen gives the impression that deviant behaviour were less elicited as the Malay female juvenile detainees were mostly busy focusing on the 
activity at hand. It has strongly indicated that deviant behaviour can be significantly reduced if the Malay female juvenile detainees were given certain tasks to accomplished especially things which were closely connected to themselves (oneself), or bring benefits and interest to them.

In overlying these study's findings, it is highly suggested that there were further studies in the future especially using qualitative study focusing on the changing phenomenon of Malay younger generation's culture especially in life norms, belief, perceptions and nurturing concepts in explaining the deviant behavior.

\section{References:-}

1. Baker, K. (2006). Understanding violent and antisocial behavior in children and adolescents. Current Paediatrics. 16, 472-477. http://dx.doi.org/10.1016/j.cube.2006.08.011

2. Baron, S. W. (2003). Self-control, social consequences, and criminal behavior: Street youth and the general theory of crime. Journal of Research in Crime and Delinquency, 40(4), 403-425. http://dx.doi.org/10.1177/ 0022427803256071

3. Bassey, Ubangha Monday; Makinde, Bola; Rasheed Ajani, Idowu; \&Olumide, Ogunyemi Michael. (2013). Relationship between Drug Abuse and Deviant Behavior among Undergraduate Students of University of Lagos, Nigeria.

4. Borum, R. (2000). Assessing violence risk among youth.Journal of Clinical Psychology,56, 1263-1288.

5. Department of Social Welfare (2013).Laporan statistic 2011. Retrieved from http:www.jkm.gov.my/

6. Duffy, Amanda L. \&Nesdale, Drew. (2008). Peer Groups, Social Identity, and Children's Bullying Behaviour. Social Development. 18. 1, 121-139.

7. Malaysian Adolescents: A cross sectional survey among secondary school students in Negeri Sembilan. Annuals Academy of Medicine, 36 (3), 169-174.

8. Ojala, Kris \&Nesdale, Drew. (2004). Bullying and social identity: The effects of group

9. norms and distinctiveness threat on attitudes towards bullying. British Journal of Developmental Psychology. 22, 19-25.

10. Paluck, Elizabeth Levy \& Shepherd, Hana. (2012). The Salience of Social Reference: A

11. Field Experiment on Collective Norms and HarrassmentBehaviour in a School Social Network.Journal of Personality and Social Psychology. 103. 6, 899-915.

12. Statistic Service, Malaysia Welfare Department.http://www.jkm.gov.my

13. Turner, J. C. (1987). Rediscovering the Social Group: A Self-Categorisation Theory. Oxford: Blackwell.

14. Unruh, Povenmiro-Kirk \& Yamamoto, 2009).Unruh D., T. Povenmiro-Kirk and S.

15. Yamamoto, (2009).Perceived barriers and protection factors of juvenile offenders in their developmental pathway to adulthood. Journal of Correctional Educational. (60) 3, pp. 201-224.

16. Wan Pung,Pit; Yaacob, Siti Nor; Baharudin, Rozumah\& Osman, Shuhaily. (2015). Low Self-Control, Peer Delinquency and Aggression among

17. Weerman, F. M., \&Hoeve, M. (2012). Peers and delinquency among girls and boys: Are

18. sex differences in delinquency explained by peer factors? European Journal of Criminology. 9 (3), 228-244. 